\title{
EDITORAS PALLAS, CORRUPIO E MAZZA: PIONEIRISMO E PUBLICAÇÃO NEGRA NO BRASIL
}

\author{
Pallas, Corrupio and Mazza: \\ Pioneering and black publishing in Brazil \\ Pallas, Corrupio y Mazza: \\ Editoriales negras pioneras en Brasil
}

Ana Elisa Ribeiro

Docente do Centro Federal de Educação Tecnológica de Minas Gerais

anadigital@gmail.com

Maria do Rosário A. Pereira

Docente do Centro Federal de Educação Tecnológica de Minas Gerais

mariadorosario58@gmail.com

\section{Resumo}

Neste artigo, à luz dos estudos de edição e considerando questões raciais, reunimos três narrativas sobre três casas editoriais brasileiras voltadas à publicação de autores e autoras negros/as, todas fundadas entre os anos 1970 e início de 1980: Pallas Editora, Editora Corrupio e Mazza Edições. Consideramos tais editoras pioneiras em sua atuação claramente política e performativa a respeito dos temas afro, em especial pela publicação de autores/as africanos/as e afrodescendentes. Também é importante o fato de que tais editoras sejam conduzidas por mulheres, em sua maioria, negras. A fim de contribuir para uma narrativa mais justa e diversa da história editorial nacional, já que consideramos os três casos subnarrados, focalizamos tais casas e suas propostas, dentro de um cenário que observamos pela relevância e pela resistência que os caracteriza.

Palavras-chave: Produção Editorial. Autoria Negra. Editoras.

\begin{abstract}
In this paper, we group three narratives about three Brazilian publishing houses aimed at the publication of black authors, all founded between the 1970s and early 1980s: Pallas Editora, Editora Corrupio and Mazza Edições. We consider these publishers to be pioneers in their clearly political and performative work on Afro themes, especially by the publication of African and Afro-descendant authors. It is also important that these publishers are commamded by women, mostly black. In order to contribute to a more just and diverse narrative of the national editorial history, as we consider the three sub-narrative cases, we focus on these houses and their proposals, within a scenario that we observe for the relevance and resistance that characterizes them.
\end{abstract}

Key words: Editorial Production. Black Authorship. Publishing House. 


\section{Resumen}

En este artículo, reunimos tres narrativas sobre tres editoriales brasileñas centradas en la publicación de autores negros, todas fundadas entre los años 1970 y principios de los 1980: Pallas Editora, Editora Corrupio y Mazza Edições. Consideramos que estas editoriales son pioneras en su actuación claramente política y performativa sobre temas afro, especialmente por la publicación de autores africanos y afrodescendientes. También es importante que estas editoriales estén dirigidas por mujeres, en su mayoría negras. Con la finalidad de contribuir a una narrativa más justa y diversa de la historia editorial nacional, dado que consideramos los tres casos subnarrados, enfocamos en estas casas y sus propuestas, dentro de un escenario que observamos por la relevancia y resistencia que los caracteriza.

Palabras clave: Producción Editorial. Autoría Negra. Editoriales.

\section{CONSIDERAÇÕES INICIAIS E NOSSO OBJETO}

A fundação e a direção de editoras de livros por mulheres, no Brasil, é um fenômeno recente em relação a uma história já relativamente breve, se tomarmos o século XIX como o marco de nossas atividades editoriais, com a chegada da Corte portuguesa em terras cariocas, o que também já é recente em relação a várias partes do mundo, inclusive de nossos vizinhos latino-americanos. A depender de como recortamos nosso objeto, é possível considerar, num intervalo mais dilatado de tempo, as viúvas de tipógrafos ${ }^{1}$ e empresários do ramo, que, a despeito de sua herança, não necessariamente podiam assumir os negócios após a morte do marido, mas que algumas vezes os assumiram e foram neles bem-sucedidas. No entanto, se considerarmos apenas mulheres fundadoras de editoras, sem relação necessária com heranças e outros comprometimentos compulsórios, esta história só começa a se desenhar com mais cores de meados do século XX em diante, quando começam a aparecer, na historiografia específica do livro e da edição, as primeiras e subnarradas menções à atuação de mulheres como diretoras ou fundadoras de casas publicadoras de livros.

Um exemplo possível ${ }^{2}$ é a ligeiríssima menção à escritora Maria José Dupré, então "senhora Leandro Dupré", nos anos 1940, como uma das fundadoras da prestigiosa editora Brasiliense, mais conhecida pela direção relevante de homens como Monteiro Lobato e Caio Prado Jr. Depois dela, outras mulheres passam a ter seus nomes mencionados, mas sem

\footnotetext{
${ }^{1}$ É possível verificar casos no século XIX, como o da Tipografia da Viúva Serva (MAGALHÃES, 2016), na verdade revendedora, na Bahia, de livros portugueses, ou histórias como a da Viúva Roma (BRAGA, 2019), em Pernambuco, para citar apenas duas mulheres que deram seguimento aos negócios que herdaram de seus maridos.

${ }^{2}$ Em Hallewell (2005, p. 369, menção ao ano de 1943).
} 
muitos detalhes sobre uma atuação que, pode-se dizer, fica ainda mais à sombra do que a atuação das escritoras, das mesmas décadas em diante.

O posto de editor, como se sabe, tem sido historiado no Brasil e, nas narrativas, surge como apanágio de figuras masculinas, geralmente relacionado ao poder, ao prestígio e à cultura. Dificilmente, portanto, uma mulher, dadas as condições socioeconômicas ligadas ao gênero, em determinadas épocas, poderia desempenhar um papel social tão visível e influente, menos ainda decisório em relação à inteligência, à cultura e aos livros. Aqui, é importante fazer uma distinção étnica, já que tal papel social, ou a distância até ele, esteve também desigualmente distribuída entre mulheres brancas, negras ou indígenas, sendo muito mais inalcançável para as duas últimas.

Além de um contexto social estruturado de maneira a que a mulher ocupasse papéis ligados ao espaço privado e os homens, ao espaço público, também se ligavam a estes fatores econômicos (dependência financeira), educacionais (pouco acesso à escolarização) e mesmo a ausência de pensamento sobre a condição feminina, algo que se retroalimenta justamente da possibilidade, a elas negada, de ler, acessar livros, decidir sobre os livros que querem ler e conhecer novas maneiras de pensar e agir no mundo. Nesse sentido, o feminismo, na forma de livros, leituras e debates, chegaria ao Brasil para alterar a mirada das mulheres sobre seus modos de vida, seus desejos, suas possibilidades e seu poder.

Após ondas do feminismo que concorrem para a escolarização feminina, ao voto, à participação política de maneira geral, ao controle de natalidade e outras conquistas (DUARTE, 2003), as mulheres se viram capazes de participar do espaço público também por meio da edição de livros, numa atuação conscientemente política e performativa quanto às suas bandeiras. Se, desde pelo menos o século XIX, mulheres vinham fundando e publicando jornais dirigidos às suas congêneres, Brasil adentro, com os livros isso se dá de maneira mais lenta, o que certamente tem relação com os custos e os modos de produção e circulação desse objeto.

Parece-nos relevante apontar as primeiras iniciativas de personagens negros no campo da edição, ainda no século XIX, no Brasil, como é o caso da Tipografia Fluminense de Brito e Cia. e a Empresa Tipográfica Dous de Dezembro, ambas dirigidas por Francisco de Paula Brito. Tendo sido tipógrafo na Imprensa Nacional e ainda redator e tradutor no Jornal do Comércio, em 1832 este mulato de origem humilde funda a Tipografia Fluminense, responsável pela edição do periódico A Mulher do Simplício ou A Fluminense Exaltada 
(1832-1846), ${ }^{3}$ importante defensor do avanço da condição feminina. Paula Brito é considerado o pioneiro da imprensa negra no Brasil, com a publicação, em 1833, do periódico O Homem de Cor, posteriormente chamado O Mulato ou O Homem de Cor,${ }^{4}$ tendo sido também editor de escritores de expressão, como José de Alencar e Machado de Assis, entre outros. De 1830 a 1860, estima-se que sua tipografia, a Dous de Dezembro, tenha publicado, além de inúmeros periódicos, 400 livros, o que mostra a importância dos empreendimentos de Paula Brito. ${ }^{5}$ Somente nos anos de 1970 haverá novas iniciativas editoriais visando à valorização da causa e da escrita negra.

Neste trabalho, focalizaremos três casas editoriais fundadas e dirigidas por mulheres, nos anos 1970-1980, algumas delas sendo fundadas e dirigidas por mulheres negras. O objetivo de tais iniciativas foi dar visibilidade à produção escrita afrodescendente ou negra, ${ }^{6}$ elemento que confere a esses casos ainda mais especificidade quanto ao aspecto político e fortemente ideológico desses empreendimentos, todos em atividade até os dias de hoje.

\section{UM SALTO DE DÉCADAS: EDITORAS DEDICADAS À PUBLICAÇÃO DE AUTORES/AS NEGROS/AS}

A fim de abordar as casas editoriais dedicadas à publicação de autores e autoras negros/as e o inescapável fato de que suas editoras sejam mulheres, passaremos à história concisa de cada uma dessas relevantes e pioneiras casas, que são: a Pallas, de Mariana e Cristina Warth, no Rio de Janeiro, desde 1975 (fundada pelo pai de Cristina Warth); a Corrupio, de Arlete Soares e Rina Angulo, em Salvador, desde 1979; e a Mazza Edições, de Maria Mazarello Rodrigues, em Belo Horizonte, desde 1981.

Não deve ser por acaso que a maior parte das editoras pioneiras, no século XX e póstipográficas, cujo objetivo foi publicar autores e autoras negros/as, fosse dirigida por

\footnotetext{
${ }^{3}$ Constância Lima Duarte (2016, p. 61) chama a atenção para o fato de que, em seu terceiro número, os versos o conteúdo do jornal era escrito em forma de poemas - foram assinados por "Da Autora" e, posteriormente, por "Da Redatora". A pesquisadora comenta: "Seria o caso de se pensar que o jornal teria sido da responsabilidade de uma mulher? Se assim for, esse seria o primeiro dirigido por uma mulher no Brasil! Ou a assinatura no feminino era apenas estratégia de Paula Brito?"

4 "A publicação propunha o fim da escravidão, a inserção do negro no mercado de trabalho como assalariado, a industrialização do país e a ampliação do acesso a bens e serviços culturais a toda a população. Arrisco dizer que o jornal constitui, no campo editorial, a primeira rede de sociabilidade e resistência, em cujas páginas percebe-se uma ampla fratria entre negros brasileiros." (OLIVEIRA, 2018, p. 160)

${ }^{5}$ Paula Brito se destaca por ter criado também, em 1840, uma espécie de sociedade literária, a Petalógica, na qual se reuniam intelectuais e escritores da sociedade carioca.

6 Tais terminologias nem sempre encontram consenso entre os próprios autores negros, mas, neste trabalho, utilizaremos "literatura negra", pensando num conjunto de produções que "ressignificam a palavra negro, retirando-a de sua conotação negativa, construída desde os tempos coloniais e que permanece até hoje, para fazêla significar autorreconhecimento da própria identidade" (ALVES, 2019 apud MIRANDA, 2019, p. 19).
} 
mulheres, em alguns casos por mulheres negras e, ainda, que estejam localizadas em estados do Brasil com forte histórico escravocrata. Trata-se de uma questão sociocultural evidente nessas sociedades, o que torna tais casas editoriais uma importante reação ao racismo e à invisibilidade de certa parcela da população. De outro ângulo, interessante notar que tais iniciativas editoriais tenham ocorrido, em sua maioria, fora dos centros e dos espaços hegemônicos de produção editorial no Brasil, hoje aparentemente limitados a duas das 27 unidades federativas brasileiras, à exceção da Pallas, que, ainda assim, produz um discurso contra-hegemônico, ao publicar negros e negras, desde a ex-capital federal.

Conforme Luiz Henrique de Oliveira (2018), inspirado em Henrique Cunha Jr., tais iniciativas editoriais, por se posicionarem de modo contra-hegemônico no campo literário, configuram-se à maneira de quilombos,

\begin{abstract}
entendendo esse termo em uma acepção ampliada. Henrique Cunha Jr. lembra que "o conceito de quilombo tem sido pensado no campo da identidade cultural, do território e da permanência histórica" ligados à "produção da identidade e da territorialidade". E é nesse sentido, o da produção de identidade e de territorialidade, que me valho do quilombo como metáfora para compreensão das propostas de atuação das casas editoriais negras (...) (OLIVEIRA, 2018, p. 156-157)
\end{abstract}

Sendo assim, fica patente a atuação dessas editoras como forma de resistência ao mercado estabelecido, que prioriza publicações que comumente preenchem certos requisitos: no critério gênero, a maioria dos autores publicados por grandes editoras é homem; no que se refere à cor, é branco; e no que se refere à região em que residem, a Sudeste, eixo Rio de Janeiro-São Paulo, sobretudo, como aponta Regina Dalcastagnè (2012). O panorama de publicações no Brasil seria, então, um grande "mapa de ausências", construído para referendar determinadas posições e, consequentemente, dar visibilidade a determinadas obras, ao passo que outras são excluídas. Assim, há uma série de instâncias que têm o poder de legitimar um escritor e uma obra, como as universidades - com seu poder de indicar certas leituras - e, claro, as próprias editoras. Quando um livro finalmente consegue ser publicado, ainda há outras instâncias de caráter paratextual que confluem para a adesão a uma obra, como a mídia ou a posição que um livro ocupa numa vitrine.

A cadeia do livro, então, desde o processo editorial até as mãos dos/as leitores/as, conforma um tipo de autor padrão no cenário literário, o que mostra quão importante é dar visibilidade a outros segmentos sociais. No que se refere à questão racial, mesmo as 
personagens apresentadas na ficção brasileira, sobretudo no romance contemporâneo, são brancas. Segundo Dalcastagnè, em quase 60\% dos romances pesquisados (período 19902004), publicados por renomadas editoras, ${ }^{7}$ "não há nenhuma personagem não-branca importante" (2012, p. 173-175) e, naqueles em que elas existem, menos de $6 \%$ dos protagonistas são negros. Diante desse quadro, editoras que priorizem vozes negras, representativas da diversidade existente no país, vozes dissonantes, portanto, precisam ser estudadas e reconhecidas. A literatura negra abala e fratura a ideia de uma literatura canônica unívoca. Nas palavras de Fernanda Miranda: “(...) a literatura negra não apenas cria quilombos na ordem discursiva, ela também produz uma crítica corrosiva às estruturas da casa-grande, porque nos permite ler o campo literário filtrando nele suas posicionalidades em disputa" (MIRANDA, 2019, p. 19, grifos no original)

No que se refere às primeiras iniciativas editoriais nesse sentido, ainda nos anos de 1970 e 1980, tal reconhecimento é ainda mais premente, uma vez que essas editoras abriram caminho para que, hoje, outras casas se estabeleçam com os mesmos princípios, a saber, valorizar a autoria negra como forma de perturbação do status quo e, por que não, como forma de ativismo político-cultural ${ }^{8}$.

\section{CONTRADISCURSO E PERFORMATIVIDADE NA EDIÇÃO: TRÊS EDITORAS BRASILEIRAS}

Já entrado o século XX, as casas editoriais conhecidas dedicadas à publicação principalmente de autores e autoras negros/as voltam à cena apenas nos anos 1970, a não ser

\footnotetext{
${ }^{7}$ Na pesquisa de Dalcastagnè, foram consideradas as publicações das editoras Companhia das Letras, Record e Rocco. Importante salientar que as casas de pequeno porte e as autodeclaradas "independentes" têm feito o importante trabalho de lançar livros/discursos contra-hegemônicos, como é o caso das casas aqui abordadas. Escritores e escritoras lançados/as por estas editoras podem ser legitimados e ganhar visibilidade, concorrendo com as editoras hegemônicas, como ocorre, por exemplo, à escritora brasileira Conceição Evaristo. Pode acontecer de esses escritores passarem a ser publicados pelos grandes grupos, borrando a existência de casas editoriais anteriores. Não é o que ocorre a Conceição Evaristo, que publicou pela Pallas, pela Mazza, pela Editora Mulheres e pelo grupo Quilombhoje (contos e poemas na série Cadernos Negros), tendo, ainda, publicado seu livro mais recente, Canção para ninar menino grande (2018), pela Unipalmares, pequena editora de São Paulo.

${ }^{8}$ São editoras surgidas depois dos anos 2000, em contexto social, histórico e tecnológico bem diverso de suas predecessoras, tais como: Nandyala, de Íris Amâncio, em Belo Horizonte, desde 2006; Malê, desde 2015, no Rio de Janeiro, casa publicadora de autores e autoras negros fundada e dirigida por Vagner Amaro e Francisco Jorge; Padê Editorial, coletivo fundado entre Brasília e São Paulo por duas poetas (Tatiana Nascimento e Bárbara Esmenia), em 2015; Figura de Linguagem, fundada em 2018, em Porto Alegre, por Fernanda Bastos e Luiz Maurício Azevedo, jornalistas e escritores negros; e Editora Unipalmares, fundada em São Paulo, muito possivelmente como iniciativa da Faculdade Zumbi dos Palmares (sem informações sobre data de criação e fundadores). As editoras mencionadas podem ser encontradas por meio de seus sites e/ou redes sociais. Algumas outras iniciativas tangenciam a questão negra, mas partem das questões de gênero, como a Ferina, de Jarid Arraes e Lizandra Magon de Almeida. Há outras, surgidas pós-2010 e herdeiras de iniciativas muito anteriores, mesmo que não tenham tido a oportunidade de conhecer narrativas sobre suas predecessoras.
} 
que outras tenham existido e tenham sido completamente apagadas pela narrativa hegemônica. De modo mais geral, tal década foi propícia ao surgimento de iniciativas editoriais que procurassem resgatar e dar visibilidade à causa negra. Alguns acontecimentos destacam-se nesse período, tanto em âmbito nacional quanto internacional, como o surgimento do Movimento Negro Unificado (MNU), no Brasil, cujo objetivo era lutar contra o racismo por meio de ações sociais, discussões políticas e culturais, bem como a independência de muitos países africanos. O ano de 1978 foi escolhido pela ONU o "Ano Internacional Antiapartheid", o que mostra que a questão racial era objeto de atenção ao redor do globo. Havia, pois, motivações de ordem política e social a fomentar o interesse editorial sobre a questão negra - ainda que, em terras brasileiras, tenham existido poucas editoras efetivamente preocupadas com a construção de um ethos editorial negro, por assim dizer.

Como iniciativas francamente ocupadas da visibilização dos negros e negras como escritores/as, intelectuais e pensadores/as, a participar do cenário e da disputa discursiva geral, as editoras Pallas, Corrupio e Mazza foram bem-sucedidas, e ainda somaram às suas preocupações as questões de gênero. Vejamos caso a caso, a fim de chegarmos a algumas considerações sobre este capítulo de nossa complexa história editorial.

\subsection{Pallas Editora}

Segundo informa sua página eletrônica, a Pallas Editora foi fundada em $1975^{9}$, na cidade do Rio de Janeiro, e "dedica parte de seu catálogo aos temas afrodescendentes". Nasceu pelas mãos de Antônio Carlos Fernandes, mas a casa, atualmente, é dirigida por duas mulheres, a filha e a neta dele, respectivamente: Cristina Fernandes Warth e Mariana Fidalgo Fernandes Warth. Trata-se, pois, de uma empresa familiar, em sua terceira geração. A Pallas declara-se "interessada na compreensão e na valorização de nossas raízes culturais e ciente do ainda precário registro dos saberes africanos na diáspora e de sua importância como uma das matrizes fundadoras de nossa nacionalidade". Desse modo e com essa consciência, a Pallas tem o objetivo de "recuperar e registrar tradições religiosas, linguísticas e filosóficas dos vários povos africanos continuamente trazidos para o Brasil durante o regime escravista".

\footnotetext{
${ }^{9}$ Segundo a narrativa de Laurence Hallewell (2005, p. 668, no capítulo 20, "Na época da 'abertura"”, em seção intitulada "A atividade editorial no setor não didático", com menção no índice remissivo), nas duas únicas linhas dedicadas à Pallas Editora, a empresa surgiu em 1980, voltada à publicação de obras sobre "nossas origens étnicas e culturais", conforme citado por ele, "e de obras infantojuvenis". A data não coincide com a informação da editora.
} 
Além disso, a casa busca acompanhar as "manifestações afro-brasileiras contemporâneas, valorizando-as como formas fundamentais de expressão da brasilidade”.

O catálogo da Pallas é composto de maneira a abarcar, segundo institucionalmente declaram, "o registro escrito das tradições orais africanas em nosso país", isto é, "literatura, passando pela antropologia, pela sociologia, por livros de referência, pelo cinema, pela filosofia entre outros". Além disso, a editora investe em produções para os públicos infantil e juvenil, “com títulos em que histórias africanas e afro-brasileiras são contadas e nos quais personagens negros ocupam o lugar de protagonistas, o que é urgente e necessário em um país mestiço como o nosso".

Além dessas linhas claramente politizadas, o catálogo da Pallas também se ocupa de temas como o tarô, a Yoga, saúde, cultura cigana, devoções e outras práticas "consagradas pela sabedoria popular". Finalmente, são mencionados os cuidados com a materialidade dos livros que produzem, apresentando "ao público leitor livros de qualidade, com projetos modernos e bem acabados, resultado do prazer que temos em fazê-los".

Observando-se o catálogo disponível no sítio eletrônico da editora, é possível constatar sua composição voltada à cultura negra e afro-brasileira, assim como seu investimento em categorias que ela organiza como: religião, magia, autoajuda, jogos, obras de referência, ciências sociais, não ficção, ficção, poesia, infantil e juvenil. Os títulos por vezes se repetem, quando cabem em mais de uma categoria, e refletem claramente a linha editorial macro da casa. São apresentados/as seus/suas autores/as, ilustradores/as e há preocupação com o atendimento de públicos específicos, tais como professores e pessoas com necessidades especiais.

Figura 1. Homepage da Pallas Editora.

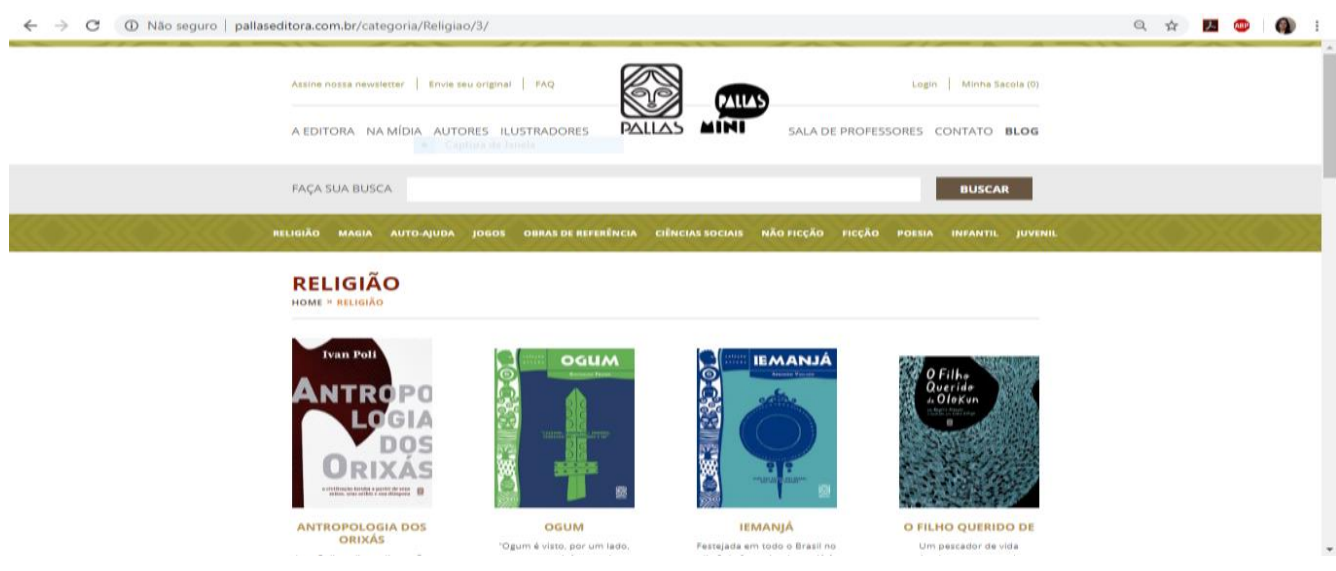

Fonte: http://www.pallaseditora.com.br/. 
Não tem sido tarefa fácil encontrar estudos sistemáticos sobre editoras de pequeno porte, em especial as pioneiras. Uma pesquisa nos filtros acadêmicos do Google mostra alguns trabalhos esparsos, tais como o de Debus (2010), dedicado à breve análise do catálogo infantil da Pallas Editora; o de Oliveira e Rodrigues (2016), em que a Pallas é mencionada entre as editoras que publicaram literatura negra, no século $\mathrm{XX}$, em um exaustivo levantamento; o de Oliveira (2018), que trata de iniciativas independentes, defendendo a noção de "quilombos editoriais", citando então a Pallas Editora como um desses quilombos; ou o de Guimarães (2016), que discute os entraves para a execução plena da lei 10.639/2003 em relação ao mercado editorial e às dificuldades de "reconhecimento do negro escrito". Segundo aponta esta autora, a nosso ver, muito acertadamente:

Embora haja constituição de um cânone euro-descendente (e masculino) pelas grandes editoras para as literaturas africanas de língua portuguesa, percebemos que a possibilidade de mudança desse quadro pode vir das editoras especializadas em temáticas afro-brasileiras e africanas - casos da Mazza Edições, Nandyala Editora e Livraria e Pallas Editora, somente para citar algumas, dentre outras menores que começam a surgir, e as corajosas, persistentes e necessárias edições de autor. Toda essa cadeia ainda não possui o fôlego financeiro para competir com as grandes editoras, mas valese de um catálogo sensível às temáticas supracitadas e maior sensibilidade para a importância do fenótipo para o escritor. (GUIMARÃES, 2016, p. 82)

Tais trabalhos de compilação e análise coincidem com os interesses de uma era da produção editorial brasileira pós-abertura democrática, sob ideais neoliberais e pós-mudanças tecnológicas em direção às digitalidades, funcionando como tentativas de revisão panorâmica de cenários e catálogos voltados a linhas específicas e, afinal, às disputas narrativas enfrentadas pelas casas editoriais surgidas com objetivos políticos claros, tais como a Pallas e congêneres.

\subsection{Editora Corrupio}

Segundo o sítio eletrônico da Editora Corrupio, a empresa foi fundada em 1979, em Salvador, Bahia, por Aparecida (Cida) Nóbrega, Rina Ângulo e Arlete Soares, mantendo-se esta última no comando da casa até 2020, quando a editora encerrou suas atividades, já durante a pandemia da Covid-19. A ideia era publicar "livros sobre culturas negras e diáspora africana. Algo incomum no mercado editorial brasileiro, hoje em expansão". O gesto editorial fundacional da Corrupio foi publicar obras do fotógrafo francês Pierre Verger, Retratos da Bahia, com o interesse de "divulgar a vasta obra do etnólogo, dedicada às relações entre a África e a Bahia". Além das culturas afro, a Corrupio "também lança olhares sobre culturas 
árabes e orientais. São livros belos, verdadeiros objetos de conhecimento”. O catálogo reúne "biografias de personalidades" (Mãe Menininha, por exemplo), receitas, ensaios e fotografias. São "grandes obras de uma pequena editora", cujo nome, Corrupio, "presta homenagem a uma rua da velha Bahia onde viveu o fotógrafo franco-baiano inspirador da criação dessa bela Casa de Edição".

Figura 2. Homepage da Editora Corrupio.

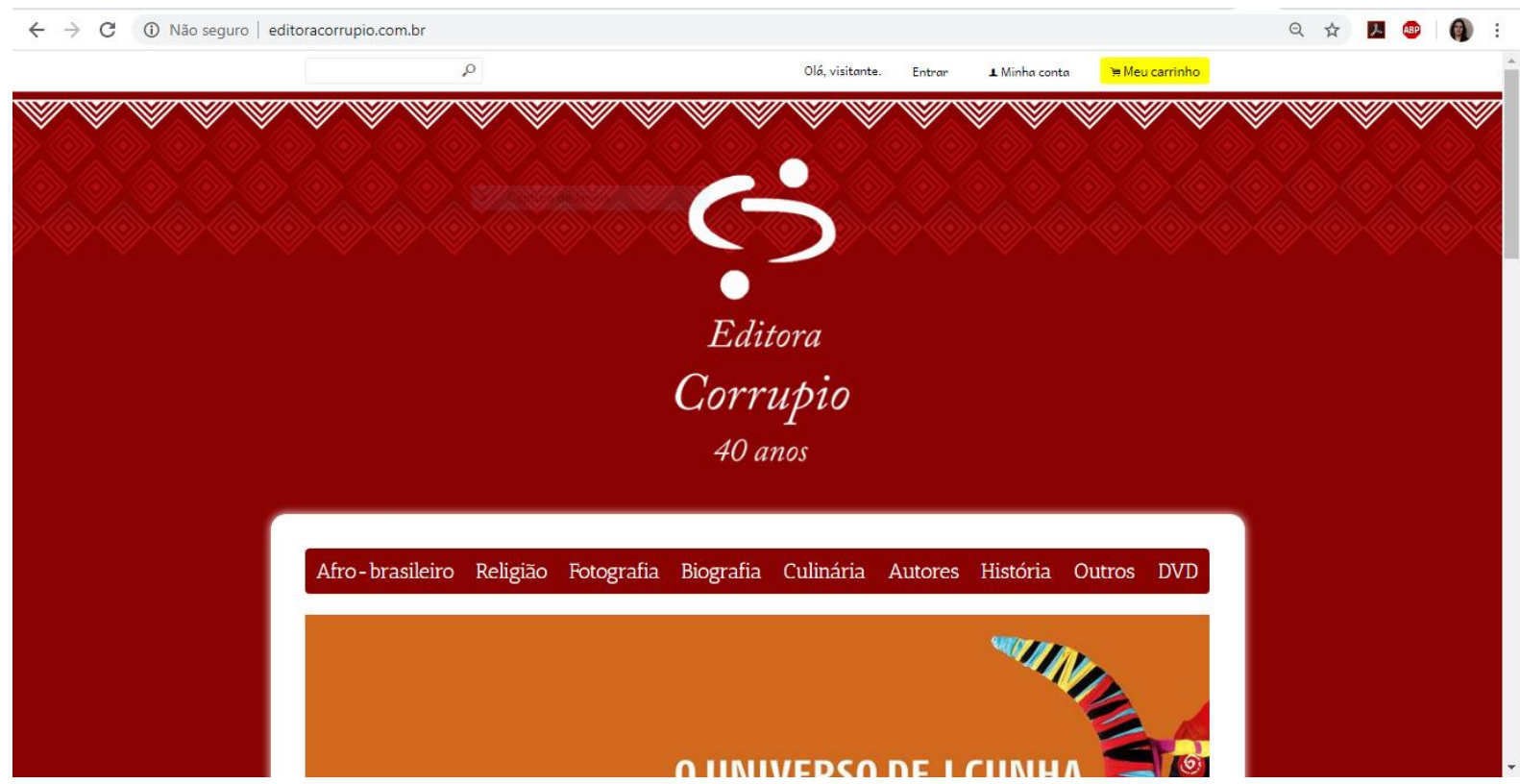

Fonte: http://www.editoracorrupio.com.br/

O catálogo da casa se organiza em: afro-brasileiro, religião, fotografia, biografia, culinária, autores, história, outros e DVD, onde a categoria "autores" diz respeito ao elenco publicado pela editora; a categoria DVD apresenta um único produto sobre a escritora Zélia Gattai; e a aba Outros, sim, ainda se subdivide em poesia, romance, psicanálise, arte brasileira, livros raros, cartazes, catálogos e postais, ainda que estas categorias não se apresentem primeiro no site.

Uma busca pela editora nos filtros do Google Acadêmico dá conta de ainda menos trabalhos sobre a Corrupio Editora. A despeito de sua já longa trajetória, ela não costuma figurar entre os objetos de estudo de diversas pesquisas, nem mesmo entre as aqui mencionadas e que se dedicam à edição sob o viés das questões afro. Embora livros da Corrupio sejam frequentemente citados em trabalhos sobre o fotógrafo Pierre Verger e outras questões de antropologia, apenas encontramos menção à casa editorial em artigos sobre a economia criativa em Salvador, cidade que, a despeito de sua evidente e inegável importância 
histórica, parece ter sua narrativa enfraquecida pela narrativa hegemônica sobre editoras no Brasil.

Oliveira, Galvão e Seidel (2014) apenas listam a casa ora em foco entre as editoras baianas, num contexto de análise das dificuldades pelas quais passa o setor editorial naquele estado. Segundo dizem as autoras e o autor, conforme seu levantamento das casas editoriais na Bahia, seria possível conhecer a dinâmica da produção nesse ramo, distinguindo entre o que chamam de editoras "formais e não formais", incluindo aí as que "trabalham de forma alternativa" (cordéis, quadrinhos e gráficas que atuam como editoras), além de lidarem com o que consideram um "difícil gargalo": a distribuição dos livros. Como sabemos, trata-se de um problema generalizado, não apenas baiano.

Rosa e Barros (2004), uma década antes do trabalho anteriormente mencionado, já propunham o desenho de um panorama da edição na Bahia, elencando entre as editoras narradas a Corrupio, sem grandes detalhamentos, dada a brevidade do artigo e seu objetivo panorâmico. As autoras apontavam que, “apesar de ter sido a primeira capital do Brasil, ter acolhido a primeira escola formal, fundada pelos jesuítas, a primeira escola de ensino superior e a primeira biblioteca pública do Brasil e da América Latina, estas não foram condições suficientes para a consolidação de uma indústria editorial em Salvador" (ROSA; BARROS, 2004, p. 12). Importante destacar, no discurso das pesquisadoras, a noção de que educação, poder e dinheiro caminham pari passu com as questões editoriais. Parece, no entanto, que essa conciliação depende ainda de outros fatores, que, no Brasil, só foram se encontrar no século XX, na região Sudeste.

Rosa e Barros (2004) escreveram seu artigo nos primeiros anos do novo milênio, quando a discussão sobre editoras independentes ainda ganhava tração no Brasil e se disseminava por vários países. De lá para cá, muitas coisas mudaram, mas talvez ainda seja necessário que pesquisadores/as baianos se preocupem em traçar panoramas e perfis de mercado tidos como "locais" ou "regionais" 10 , enquanto algumas regiões do país tratam-se

\footnotetext{
${ }^{10}$ Interessante notar que Flávia Rosa era, nesta altura, editora da Editora da Universidade Federal da Bahia EdUFBA e professora da UFBA, enquanto Susane Barros era graduanda de Biblioteconomia e pesquisadora de Iniciação Científica da mesma instituição. As autoras e o autor da outra referência mencionada, Calila Oliveira, Raquel Galvão e Roberto Seidel, atuavam na Universidade Estadual de Feira de Santana, também na Bahia, no programa de Estudos Literários. Para uma narrativa mais ampla e que faça jus a uma história realmente brasileira da edição, é fundamental que o interesse em panoramas como estes não seja apenas local. Atualmente, em São Paulo, a pesquisadora Gabriela Costa Limão desenvolve um projeto intitulado "Querida editora, a formação da editora Corrupio: entre Salvador e Paris das décadas de 1970 e 1980”, no âmbito do Instituto de Filosofia e Ciências Humanas da Universidade Estadual de Campinas, Unicamp, sob a orientação da profa. Heloísa André Pontes. Ver em <https://bv.fapesp.br/pt/bolsas/189033/querida-editora-a-formacao-da-editora-corrupio-entresalvador-e-paris-das-decadas-de-1970-e-1980/>
} 
como "nacionais". As autoras afirmam, em 2004 (p. 12), que a atividade editorial baiana era "fortemente marcada pelo entusiasmo de grupos de intelectuais e artistas, que não buscavam o retorno financeiro como objetivo principal". Tais iniciativas editoriais dependiam de aportes governamentais (o que as pesquisadoras não veem com bons olhos) e aproveitavam o ensejo para publicar e valorizar a cultura baiana, num cenário que Rosa e Barros comparam com o da música. A fragilidade da edição baiana, segundo as autoras, teria motivos como: o pequeno e médio porte das editoras, problemas de distribuição dos produtos, ausência de uma política local para o livro (compras para escolas e bibliotecas) e falta de profissionalização da cadeia de produção. Além desses elementos, outros se somavam para atrasar o panorama na Bahia, como a pobreza e o analfabetismo da população, além do número reduzido de livrarias e bibliotecas. A despeito desses números, as autoras frisam a relevância do que era, então, produzido naquele estado, numa demonstração, com a qual concordamos, de que quantidade e qualidade andam em cadências não necessariamente juntas. Temos proposto, portanto, a relevância de produções editoriais que, a despeito de serem subnarradas por uma história hegemônica e contada por vozes que partem de instâncias e lugares hegemônicos, podem e devem ser vistas por sua força política e ideológica, sendo possível, mais lentamente, observar os efeitos que produzem nos discursos as editoras como as três que aqui focalizamos.

$\mathrm{O}$ "entusiasmo de grupos de intelectuais e artistas" continua sendo a força motriz de infinitas iniciativas, Brasil e mundo afora, quando o assunto é edição. Ser grande e multinacional é exceção, o que não deve tirar a relevância e a necessidade de empreendimentos tais como os da Pallas, da Corrupio, da Mazza e de incontáveis outras casas editoriais brasileiras, cujos alcances dependem de um conjunto complexo de fatores, para além dos problemas de distribuição física. Tais fatores talvez tenham sido amenizados com a chegada, depois de 2004, da web 2.0 e do maior acesso às redes digitais pela população e pelas empresas.

\subsection{Mazza Edições}

Conforme informações encontradas no sítio eletrônico da Mazza Edições, a casa foi fundada em 1981, em Belo Horizonte, por Maria Mazarello Rodrigues, mais conhecida como Mazza - é curioso e, nada aleatório, o fato de coincidirem o nome da fundadora e o nome da editora, pois a casa editorial é, efetivamente, o espelho de sua idealizadora, que nasceu em Ponte Nova, Minas Gerais, em uma família pobre de operários. Após algum tempo, conseguiu 
um emprego como faxineira em uma gráfica, vinculada ao Programa de Assistência Brasileiro-Americano ao Ensino Elementar - PABAEE. Como demonstrava interesse pelo processo, observadora atenta, foi convidada a aprender como se dava a montagem de um livro: daí começou a trabalhar no acabamento e, depois, na composição. Como muitos editores, aprendeu o ofício na prática. A Faculdade de Jornalismo ajudou a abrir horizontes e, finalmente, foi inaugurada a Editora do Professor e a Livraria do Estudante, em parceria com Anna Lúcia Campanha Baptista. Posteriormente, fundou a Editora Vega, nos anos 1970, e cursou o Mestrado em Editoração, em Paris. Foi no exterior que Mazza despertou seu interesse por questões identitárias e por autores e publicações que expressassem esse ponto de vista:

Naquela época, já estava pipocando a questão dos movimentos negros (...) Eu fui acompanhando aquela discussão. Havia reuniões na universidade sobre a questão da negritude. Os grupos faziam diversas reivindicações, entre elas questões relacionadas com a publicação de livros de autores negros. Era uma novidade pra mim e fui ficando antenada para os autores negros que eram publicados na Europa. (...) E fui prestando atenção naquilo, elaborando, até que cheguei à seguinte conclusão: eu entendo de edição, entendo de gráfica, sou uma mulher negra, uma editora negra, na hora que eu voltasse... Aquela ideia foi amadurecendo. (SANTANA-GOMES et al., 2015, p. 61-62)

Mazza acabou por fundar uma editora que, dos anos de 1980 até os dias de hoje, teve e tem grande alcance, sendo responsável pela publicação de obras que ajudam a modificar certo pensamento branco e eurocêntrico predominante no quadro de publicações nacional. ${ }^{11}$ No site encontram-se os objetivos da editora: "Ao longo de mais de trinta anos de atividades, Mazza Edições reafirma seu compromisso de levar o melhor da cultura brasileira e afro-brasileira aos seus leitores". Ainda, a editora se propõe "atuar com sentido crítico para oferecer aos seus leitores e clientes obras que contribuam para uma melhor compreensão do passado, do presente e do futuro a ser construído".

Ainda que a Mazza Edições seja razoavelmente bem conhecida (e reconhecida), sobretudo no meio acadêmico, chama a atenção o fato de existirem poucos trabalhos acadêmicos a ela dedicados (matérias jornalísticas há muitas). Santana-Gomes (2018) salienta que uma investigação realizada no banco de dissertações e teses da Capes não apresentou

\footnotetext{
${ }^{11}$ Atualmente, para além do fato de existirem outras editoras voltadas a publicações de autores/as negros/as, destacam-se também outras iniciativas nesse sentido, como a Livraria Africanidades, em São Paulo, e a Livraria Kitabu, no Rio de Janeiro, bem como o Mulheres Negras na Biblioteca - coletivo que questiona a ausência de autoras negras em bibliotecas - e o projeto Diálogos insubmissos de mulheres, com encontros, palestras e eventos que visam à divulgação e à discussão de textos de autoras negras.
} 
resultados, isto é, não constam trabalhos sobre a figura de Maria Mazzarelo e sua trajetória de vida - o que demonstra, novamente, o quanto a história de mulheres à frente de casas editoriais simplesmente não é narrada. A escassa fortuna crítica existente apresenta dados sobre a estrutura da editora, seu catálogo, e atrela esses dados a aspectos relacionados à negritude. Quanto aos trabalhos acadêmicos, Oliveira (2018) dedicou à Mazza parte de um artigo acadêmico publicado na revista Aletria (UFMG), no qual discorre também sobre outras editoras negras; Santana-Gomes et al. (2015) produziram material inestimável no que diz respeito ao resgate da memória da Mazza, numa coleção denominada Edição e Ofício, a qual teve circulação restrita entre alunos e professores do curso de Letras do CEFET-MG, cujo enfoque é a área de edição. ${ }^{12}$ Além deste material, destaque-se também artigo publicado por Santana-Gomes (2018) na revista Littera Online, no qual a pesquisadora investiga a Mazza Edições sob a perspectiva da análise do discurso e de sua trajetória de vida, por meio de considerações sobre um documentário autoral acerca da vida de Maria Mazzarelo. ${ }^{13}$ Como se percebe, são raros os trabalhos acadêmicos, o que aponta para a necessidade de maior produção de um discurso contra-hegemônico também na academia.

Figura 3. Homepage da Mazza Edições.

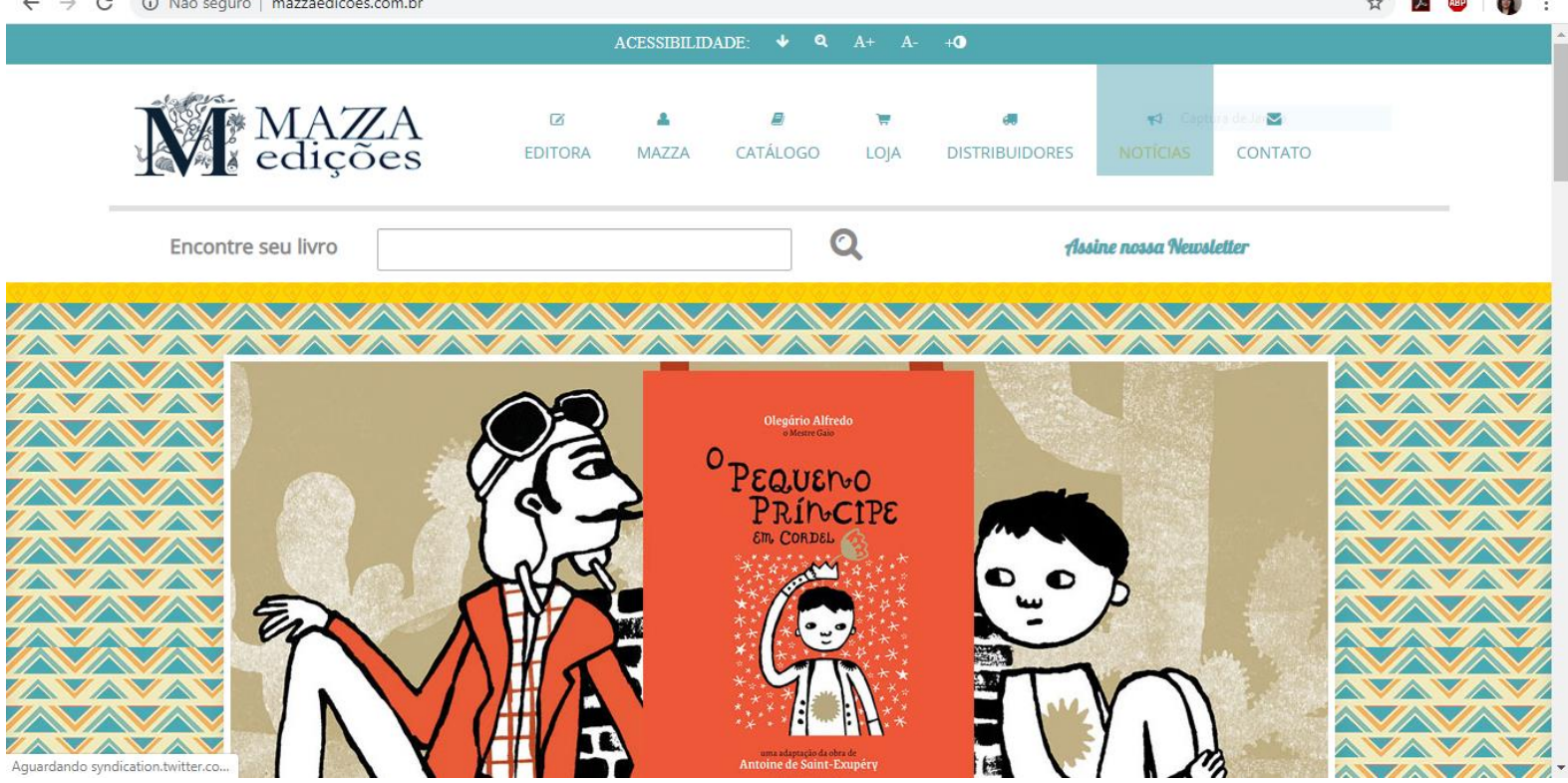

Fonte: http://www.mazzaedicoes.com.br/

\footnotetext{
12 Sob a coordenação do professor Pablo Guimarães, a Coleção Edição e Ofício produziu quatro livros que resgatam a história editorial de Maria Mazarello Rodrigues, Sonia Junqueira, Antonieta Cunha e Sebastião Nunes. Os livros consistem em depoimentos dos/as próprios/as editores/as, colhidos e transcritos pelos/as alunos/as.

${ }^{13}$ Por uma memória editorial é um filme-vídeo produzido por Letícia Santana Gomes. (Belo Horizonte: CEFETMG, 2015).
} 
A construção do catálogo da Mazza Edições pauta-se por publicações que privilegiam escritores e leitores "que acreditam na construção de uma sociedade baseada na ética, na justiça e na liberdade", conforme informações do site. A primeira publicação foi Essa história eu não conhecia, que retratava a chegada dos escravos africanos no Brasil, vendido praticamente de porta em porta - ou melhor, de escola em escola, uma vez que objetivava alcançar professoras negras e alunos -, a preço de custo. Mais adiante, o primeiro trabalho que conferiu visibilidade à editora e abriu portas para novas publicações foi a coleção Minas e Mineiros, cujo primeiro título foi Assim se benze em Minas Gerais: um estudo sobre a cura através da palavra, de Edmilson de Almeida Pereira, hoje conhecido poeta e, àquela época, estudante, e sua então orientadora, a professora Núbia Pereira de Magalhães Gomes. A obra recebeu menção honrosa no Concurso Nacional de Folclore Silvio Romero/Funarte, em 1987. Posteriormente, Edmilson, que além de poeta é professor da Universidade Federal de Juiz de Fora, tornou-se conselheiro editorial da Mazza.

A editora ocupou-se, então, segundo sua página institucional, de investir "na publicação de autores/autoras negros(as) e de livros que abordam os diversos aspectos da cultura afro-brasileira relacionada, por sua vez, a um largo segmento das populações excluídas no Brasil”. Fica nítido o caráter político-pedagógico da Mazza, que procura preencher lacunas históricas na edição brasileira, tornando-se, por isso, referência para pesquisadores e leitores, tanto em âmbito nacional quanto internacional. Destacam-se em seu catálogo as áreas de antropologia, sociologia, história, educação - incluindo publicações didáticas e paradidáticas que salientam a formação multicultural e étnica do Brasil -, literatura brasileira, bem como literatura infantil e infantojuvenil. Destaque especial deve ser dado ao mais novo selo da editora, Penninha Edições, dedicado às publicações infantis. Tal segmento tem se mostrado um dos carros-chefe da casa editorial, que vem investindo cada vez mais na qualidade dessas publicações, com ilustrações e projeto gráfico atrativos. Há também uma coleção intitulada "De lá pra cá", que relê clássicos infantis. Nessas releituras, as personagens são negras e há um diálogo entre o enredo e a cultura africana ou afro-brasileira, permitindo que potenciais leitores se identifiquem com as histórias.

\section{CONSIDERAÇÕES FINAIS: PELAS BORDAS}

Embora a Pallas Editora, primeira das casas brasileiras modernas a se dedicar à negritude, desloque-se um tanto do perfil das suas pares Mazza e Corrupio, estas dirigidas por 
mulheres negras desde Minas Gerais e da Bahia, é importante aqui tratá-la pelo que efetivamente faz, alinhando-se, aí sim, às suas congêneres: criar espaços e tempos de perturbação de um discurso e de práticas hegemônicas que, desde o mercado editorial, terminam por abranger a sociedade, o pensamento e o debate público. Mesmo estando em um centro difusor como o Rio de Janeiro, e talvez em vantagem por isso, a Pallas escolhe o atrito e um outro olhar sobre a edição. Em todos os casos, era necessário "comer pelas bordas", ocupando, inicialmente, uma posição periférica, geográfica (nos casos da Corrupio e da Mazza) e discursiva ou editorial (em todos), mas, depois, com mudanças sociais e legais ocorridas no Brasil, chegando ao posto de "pioneiras" e "fundadoras". Sem minorar a importância da revisão do panorama literário a fim de incluir autores/as negros/as, parece-nos importante que, em uma medida não desprezível, eles/as existem porque nascem, muitas vezes no mesmo gesto editorial, as editoras negras, em dois sentidos: no da publicação de negros e elas mesmas negras, em dois terços dos nossos casos.

Para quem escolhe atuar (porque edição é agência) contra-hegemonicamente, é importante considerar o maior atrito e ritmos mais lentos no alcance de objetivos. No entanto, esse alcance, para os casos aqui focalizados, é incontestável. Mesmo que ainda pouco narradas, tais editoras são hoje objeto de estudos científicos, compuseram uma bibliografia que é disseminada, efetivamente incorporada, e deram imensa contribuição ao debate público, em várias áreas do conhecimento. São o suporte de muitos/as pesquisadores/as e autores/as, negros/as ou não, na literatura e em outros campos, com seu ritmo lento e persistente, muitas vezes sob ataque. Tanto a Mazza quanto a Corrupio entram em cena sem ocupar posições geográficas e discursivas centrais, mas atuam pelas laterais, pelas bordas, funcionando como alternativas sérias e hoje legitimadas ao que é hegemônico, o que faz com que o debate possa avançar. Com este trabalho, esperamos ter reunido três casos exemplares, hoje alçados ao posto de fundadores e pioneiros, de edição negra no Brasil, orgulhosamente longevos e resistentes.

\section{REFERÊNCIAS}

BRAGA, Carolina de Toledo. Viuvez e cotidiano das mulheres em meados dos oitocentos (Pernambuco, 1942-1953). 171p. Dissertação (mestrado em História Social). Universidade Federal Fluminense, 2019.

DALCASTAGNÈ, Regina. Literatura brasileira contemporânea: um território contestado. Vinhedo: Editora Horizonte; Rio de Janeiro: Editora da UERJ, 2012. 
DEBUS, Eliane Santana Dias. A temática étnico-racial nos livros infantis da Pallas Editora. II CONGRESSO INTERNACIONAL DE LEITURA E LITERATURA INFANTIL E JUVENIL, I FÓRUM LATINO-AMERICANO DE PESQUISADORES DE LEITURA. Anais... Porto Alegre, PUC RS, 12 a 14 maio, 2010. Disponível em: <https://editora.pucrs.br/anais/IICILLIJ/4/ElianeDebus.pdf>. Acesso em: 2 maio 2020.

DUARTE, Constância Lima. Feminismo e literatura no Brasil. Estudos Avançados, v. 17, n. 49, p. 151-172, 2003.

DUARTE, Constância Lima. Imprensa feminina e feminista no Brasil: século XIX - Dicionário ilustrado. Belo Horizonte: Autêntica Editora, 2016.

GUIMARÃES, Geny Ferreira. Mercado editorial brasileiro: seus entraves para a aplicação da lei 10.639/2003 e o permanente não reconhecimento do negro escrito. IV Seminário Pensando Áfricas e suas diásporas. Anais... Universidade Federal de Ouro Preto, MG, 2016. Disponível em: <https://periodicos.ufop.br/pp/index.php/pensandoafricas/article/viewFile/1359/1097>. Acesso em: 2 maio 2020.

HALLEWELL, Laurence. O livro no Brasil: sua história. Trad. Maria da Penha Villalobos, Lólio Lourenço de Oliveira e Geraldo Gerson de Souza. 2 ed. rev. amp. São Paulo: EDUSP, 2005.

MAGALHÃES, Pablo Antonio Iglesias. As servinas em Portugal: a rede comercial intercontinental de livros impressos na Bahia colonial. Topoi (Rio J.), Rio de Janeiro, v. 17, n. 32, p. 223-256, jan./jun. 2016.

MIRANDA, Fernanda R. Silêncios prescritos: estudo de romances de autoras negras brasileiras (1859-2006). Rio de Janeiro: Malê, 2019.

OLIVEIRA, Luiz Henrique Silva de. Os quilombos editoriais como iniciativas independentes. Aletria, Belo Horizonte, v. 28, n. 4, p. 155-170, 2018. Disponível em:

<https://periodicos.ufmg.br/index.php/aletria/article/view/18829/15794>. Acesso em: 20 abr. 2020.

OLIVEIRA, Luiz Henrique Silva de; RODRIGUES, Fabiane Cristine. Panorama editorial da literatura afro-brasileira através dos gêneros romance e conto. Em Tese, v. 22, n. 3, p. 90-107, 2016. Disponível em: <http://www.periodicos.letras.ufmg.br/index.php/emtese/article/view/11269/10712>. Acesso em: 2 maio 2020.

OLIVEIRA, Calila das Mercês; GALVÃO, Raquel Machado; SEIDEL, Roberto Henrique. Dinâmicas da economia criativa do livro na Bahia. Antares, vl. 6, n. 12, p. 152-167, jul/dez 2014. Disponível em: <http://ucs.br/etc/revistas/index.php/antares/article/view/3180/1812>. Acesso em: 2 maio 2020.

RIBEIRO, Ana Elisa; VINÍCIUS, Mário (Org.). Minas GeoGráfica: casas editoriais mineiras séc. XX-XXI. Belo Horizonte: Impressões de Minas, 2019.

ROSA, Flávia Goullart Mota Garcia; BARROS,Susane Santos. Panorama da história da editoração em Salvador/Bahia. I SEMINÁRIO BRASILEIRO SOBRE LIVRO E HISTÓRIA EDITORIAL. Anais... Rio de Janeiro, UFF/Casa de Rui Barbosa, p. 1-12, 8 a 11 nov. 2004. Disponível em: $\langle$ http://ww.livroehistoriaeditorial.pro.br/pdf/flaviagoullartesusanesantos.pdf $>$. Acesso em: 2 maio 2020 . 
SANTANA-GOMES, Letícia et al. (Org.). Maria Mazarello Rodrigues. Belo Horizonte: CEFETMG, 2015. (Coleção Edição e Ofício)

SANTANA-GOMES, Letícia. Mulher, pobre e negra: análise discursiva da editora mineira independente Maria Mazzarelo (Mazza Edições). Littera Online, Programa de Pós-Graduação em Letras, Universidade Federal do Maranhão, 17, 2018.

\section{Original recebido em: 12 de maio de 2020}

Aceito para publicação em: 22 de outubro de 2020

\section{Ana Elisa Ribeiro}

Doutora em Estudos Linguísticos pela Universidade Federal de Minas Gerais. Docente e pesquisadora do Bacharelado em Letras e do Programa de Pós-Graduação em Estudos de Linguagens do Centro Federal de Educação Tecnológica de Minas Gerais (CEFET-MG). Coordenadora do grupo de estudos Mulheres na Edição.

\section{Maria do Rosário A. Pereira}

Doutora em Estudos Literários pela Universidade Federal de Minas Gerais. Docente dos cursos técnicos e da graduação em Letras do Centro Federal de Educação Tecnológica de Minas Gerais (CEFET-MG) e do Programa de Pós-Graduação em Letras da Universidade Federal de Viçosa (UFV). Coordenadora do grupo de estudos Mulheres na Edição.

\section{(9) $(0 \Theta 0$}

Esta obra está licenciada com uma Licença Creative Commons Atribuição-NãoComercial-CompartilhaIgual 4.0 Internacional 